\title{
La construcción del discurso político de los hidalgos norteños en Castilla
}

\section{The construction of the political discourse of the northern nobles in Castile}

\author{
Osvaldo Víctor Pereyra \\ vopereyra@gmail.com \\ Centro de Historia Argentina y Americana - \\ Universidad Nacional de La Plata, Argentina
}

Recepción: 05 Agosto 2020

Aprobación: 25 Noviembre 2020

Publicación: 04 Enero 2021

Cita sugerida: Pereyra, O. V. (2021). La

construcción del discurso político de los hidalgos

norteños en Castilla. Trabajos y Comunicaciones,

(53), e140. https://doi.org/10.24215/23468971e140

\begin{abstract}
Resumen: El presente trabajo se analizan los elementos fundantes que configuran el discurso político de los miembros principales del grupo de hidalgos norteños -parientes mayoresa través de la utilización de las crónicas banderizas y literatura de la época. Nos centraremos específicamente en los elementos empleados por estos sectores principales representantes de linajes vasco-cantábricos para definir su posición diferenciada frente al resto de convecinos durante el siglo XV-XVI.
\end{abstract}

Palabras clave: Hidalgos, Discurso político, Diferenciación, Castilla.

\begin{abstract}
The present work analyzes the foundational elements that make up the political discourse of the main members of the northern nobility group - parientes mayores- through the use of the chronic of sides and literature. We will focus specifically on the elements used by these main sectors representing BasqueCantabrian lineages to define their differentiated position vis-àvis the rest of the convecines during the 15 th-16th century.
\end{abstract}

Keywords: Low nobility, Political discourse, Differentiation, Castile.

\section{INTRODUCCIÓN: LOS "PARIENTES MAYORES"}

En una primera aproximación, debemos tener en cuenta que la sociedad septentrional bajo medieval y temprano moderna se encontraba estructurada en torno a grupos familiares extendidos que reciben el denominador común de «bandos linajes». De esta manera, nociones documentales tales como «estirpe», «casa», «solar», etc., aparecen referenciando a una visión de un entramado social profundamente articulado y jerarquizado desde su propia base social (J. L. Orella Unzué, 2013, pp. 67-119). Podemos definir a estos bandos linajes como la estructura básica de organización familiar que dota de coherencia a los grupos más prósperos e influyentes de la sociedad cántabra-vizcaína en estos tiempos (J. A. Solórzano Telechea, 2004, pp. 178-201). Consistentes en un grupo de descendencia patrilineal, se encuentran unidos por firmes lazos de parentesco (natural o artificial) integrando en su seno tanto a padres, hijos y parientes cercanos, pudiendo englobar también a otros grupos familiares que constituían sus extensas clientelas dependiendo, en ese caso, del poder político y económico alcanzado por el cabeza de linaje o pariente mayor. De esta manera, podemos consignar distintos círculos de dependencia y lealtad que se estructuraban en torno a estos parientes mayores 
(J. A. Marín Paredes, 1998) los cuales eran considerados o reputados, por el conjunto de sus convecinos, como «hidalgos principales»o «notorios».

Sin embargo, es necesario recalcar aquí, que no todo hidalgo norteño ${ }^{1}$ puede ser considerado un pariente mayor. Para alcanzar este «estatus diferencial» dentro de sus respectivas comunidades de origen debían ser estimado como descendientes de un «solar conocido», tener una preponderancia política «local», consignar suficientes recursos económicos para movilizar a su favor una amplia «clientela», gozar de un «prestigio» propio en sus comunidades de origen, etc., así como todo un conjunto de rasgos subsidiarios que iremos describiendo a lo largo de este artículo, que forman parte de la constitución de una «imagen global», un «discurso político» propio de estos sectores principales que — durante los siglos XIV al XVIvan consolidando en el imaginario colectivo su situación como el grupo más acendrado y próspero del tejido societario del septentrión peninsular. ${ }^{2}$ Simplificando extremadamente la imagen, por un lado, podemos señalar un grupo, más o menos extenso, de hidalgos locales poderosos que en función de su categoría aparecen vinculados a dominios señoriales - laicos y monásticos - y que son percibidos por los convecinos como linajes «preeminentes»-es decir, de «antigua y conocida prosapia»- reputados como principales dentro de los espacios regionales y comarcales en los cuales se encontraban implantados, por el otro, un segmento inferior de «hidalgos pobres», mucho más numeroso, sumidos en una condición económica bastante parecida a la de los labradores: “... ya que ellos vivían en los lugares de behetría, abadengo, o solariego, labraban y debían hacer en los solares los fueros e rentas que hacían los labradores, incluida, en ocasiones la prestación de trabajo" (C. Díez Herrera, 1990, p. 258; L. Da Graca, 1996). Es decir, no es viable en los espacios septentrionales subsumir la categoría de hidalgo a la de señor -aunque compartan la misma base de privilegio jurídico- algunos pueden ser catalogados como «señores sin señorío» pero en su inmensa mayoría eran agricultores apegados a su terruño y aldea. ${ }^{3}$ Podemos afirmar que hidalguía y pobreza no sólo podían ser compatibles en España, sino que, en el espacio septentrional del reino de Castilla era una realidad extendida y constante. Un ejemplo claro de ello lo tenemos en el propio Quijote.

En este sentido, entendemos que es necesaria una «inversión de nuestra mirada» o, si se prefiere, una «complementación», ya que el rol de la pequeña nobleza no puede ser reducido a un simple apéndice de la alta aristocracia castellana ni debería ser estudiada por fuera del contexto social, económico y político que conforma su situación diferenciada al interior de las aldeas y villas donde intentan imponer - no sin tensiones y conflictos - sus privilegios frente al resto de sus convecinos. Debemos establecer sobre esta pluralidad de familias hidalgas lo que definiríamos como una mirada «diferenciadora» y «diferenciante» anclada en analizar el propio protagonismo que aquéllas tienen en el complejo juego político al interior de sus comunidades locales plenamente jerarquizadas y donde la participación de estos efectivos humanos, enrolados en los distintos bandos linajes y parcialidades, se torna fundamental al momento de analizar la conflictividad interna que presentan las mismas. ${ }^{4}$ Dentro de este complejo entramado societal, el cabeza del linaje o pariente mayor era considerado el primogénito de la rama principal, y actuaba como un jefe sobre los distintos miembros del linaje convirtiéndose así en rector de este (A. Dacosta Martínez, 1999a; 2003). Su autoridad era moral y política en cuanto atendía los asuntos de su propia casa, pero también era intermediario, última voz y decisiva, en término de las querellas de otros núcleos parentales desprendidos del tronco familiar. ${ }^{5}$ Desde fines de la Edad Media se había convertido en jefe del entierro del linaje y por lo tanto guarda de la tumba familiar de sus antepasados. Era el encargado, por delegación testamentaria, de cuidar y velar por el reposo de sus almas con lo cual, en definitiva, era guardián de la memoria colectiva propia del linaje. De esta manera linaje, solar $^{6}$ y memoria ${ }^{7}$ se constituían en una unidad de sentido global que identifica al pariente mayor y al conjunto estructurado vinculados a él. ${ }^{8}$ El cabeza del linaje era también el patrono de las diferentes capellanías e iglesias familiares fundadas por sus antecesores que hacían recaer en el primogénito el cuidado de estas. ${ }^{9}$ Muchas veces se daba el caso de que se nombraba al frente de estas iglesias un miembro del propio linaje ya que la opción de las vocaciones religiosas masculinas y femeninas se conformaban como 
otra de las vías de promoción y acumulación que permitía acomodara segundones y ramas colaterales de la nobleza laica. De la misma manera la cohesión simbólica implicaba la idea de que cada linaje noble poseía un apellido (o patronímico) y escudos de armas que los distinguía del resto de la población. ${ }^{10}$ Como vemos la figura misma del pariente mayor condensa sobre su persona este conjunto plural de relaciones establecidas en función del solar y del linaje, adicionando el de la autoridad, ya que a su voz de mando se ponía en pie de guerra toda la parentela, los sujetos vinculados y dependientes, así como sus respectivas clientelas.

\section{EL TOPO-DISCURSO: LOS ELEMENTOS DE TERRITORIALIDAD UNIDOS AL SENTIDO DEL LINAJE.}

Según L. García de Salazar los linajes tenían un origen inmemorial, perdido en la "nebulosa de los tiempos". Desde una visión "teleológica" siempre los hubo y siempre los habrá. Para el cronista banderizo los mismos deben ser vistos con un origen, una «raíz», consistente en un antepasado remoto, a partir del cual “... se sucedieron... y suceden... unos en otros” (L. García de Salazar 1492 [1999], p.851). Sin embargo, si bien el origen arcaico del fundamento es un elemento necesario y significativo para su estructuración también debemos ponderar que es un parámetro insuficiente; es decir, junto con él debe funcionar otro elemento de identificación que, según el propio autor, se encuentra materializado en el solar. «Solar y linaje» son así elementos reducibles, en tanto el antiguo solar funciona como punto convergente, que otorgan sentido a la procedencia y sucesión, un «locus territorial» que se encuentra fijado materialmente en la memoria. Tomemos por ejemplo la mención que hace el autor de las Bienandanzas e fortunas sobre los grupos familiares principales asentados "en el valle de Guriezo... ay tres linajes, que antiguamente sucedieron del solar de Palaçio, que es allí en Guriezo, acerca de la iglesia de Sant Viçente de la Maça, donde está una torre vieja." (L. García de Salazar 1492 [1999], p.855). Como vemos, el autor pone énfasis en tres elementos materiales de referencia territorial que permiten establecer la procedencia de los linajes: el valle, la antigua iglesia y, finalmente, una primitiva torre. Lo importante para el cronista es identificar, localizar, aquellos elementos que, dentro de la memoria de los pobladores del lugar, era el antiguo solar del linaje de los Palacio. Es un claro ejemplo de la centralidad que adquiere el «locus territorial» en la construcción del aparato discursivo de este grupo de poder. A pesar de la necesidad de L. García de Salazar de señalar puntillosamente el solar originario, de identificarlo territorialmente, no muestra el mismo interés en señalar, por ejemplo, la relación parental que estructuraba a los tres linajes originarios surgidos de aquel primitivo solar. De esta manera, las nociones de «linaje»y «solar» se nos presentan como dos elementos que funcionan en conjunto, imposibles de separar en este tipo de narraciones. Es más, podríamos decir que las «relaciones parentales» son en algún punto complementarias y marchan conspicuamente adosadas a las anteriores, entendidas más bien como un sistema de legitimación amplio. Dicha situación queda a nuestro juicio claramente graficada si nos atenemos también al hecho de la consideración positiva que adquiere en este tipo de relato genealógico el esquema del «héroe bastardo» como elemento originario de muchos de estos linajes de los espacios septentrionales del reino castellano. Para este tipo de crónica banderiza lo importante es resaltar la línea de sucesión del linaje de «varón a varón», preferiblemente. Si dicho garante es también el primogénito legítimo, mucho mejor, pero dicha vertebración no es del todo excluyente de otras formulaciones. ${ }^{11}$

Ahora bien, siguiendo historiadores vascos como J. R. Díaz de Durana (1998b, pp.235-260) y A. Dacosta Martínez (2003, pp. 95-112), suprimir el estudio de las «bases materiales del poder de los parientes mayores» presentan dos niveles subsidiarios e importantes a tener en consideración, por un lado, el conocimiento del flujo de rentas y explotaciones plurales de los que participa cada linaje y, por otro lado, el conjunto del patrimonio inmueble alcanzado. El caso que nos interesa en este momento es el segundo de ellos, es decir, aquel en que encontramos estas edificaciones como manifestación material del poder alcanzado.

Dichas construcciones forman parte del conjunto de elementos que, territorialmente instalados, marcan o señalan la preeminencia política del pariente mayor. Son en su conjunto, de alguna manera, la forma objetiva en la cual se cristalizan en torno a su figura un cúmulo de relaciones de dependencia y sujeción que componen 
el reconocimiento de su posición privilegiada frente al resto de sus convecinos. Podemos tomarlos como «signos» materiales del poder alcanzado y del lugar de prevalencia que en cada espacio territorial alcanzan los mismos, manifestando así un discurso pétreo. La importancia que adquieren las mismas como representación arquitectónica del poder del linaje puede observarse en el hecho de que las mismas se convierten en objetivo de los conflictos y disputas, permanentes, de las acciones de los bandos enfrentados, no solo por su alto valor simbólico sino también de su valor estratégico desde el punto de vista militar y tributario. Desde el punto de vista tributario, eran las fuentes de concentración espacial de la renta. De esta manera, su alzamiento o su destrucción marcan o simbolizan un acrecentamiento o una disminución del poder del pariente mayor, es así como la defensa y el mantenimiento se convierte en uno de los deberes centrales del cabeza de linaje. En un texto como las Bienandanzas e Fortunas el número de relaciones directas enfatizadas por el autor sobre estas manifestaciones materiales del poder en los distintos espacios es, sin duda, notable. ${ }^{12}$

\section{Cuadro 1: Frecuencia de locativos}

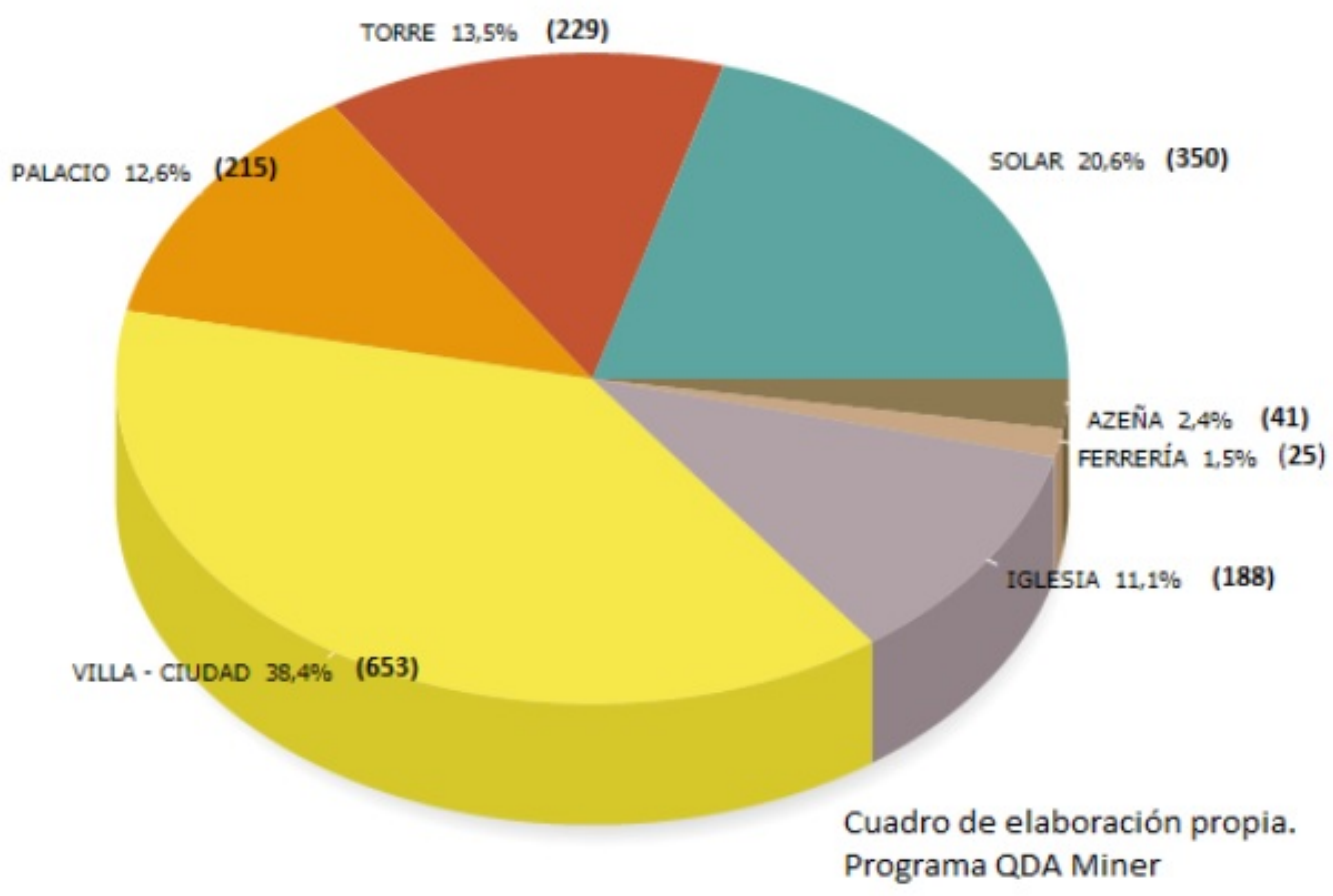

Dichas edificaciones configuran lo que podríamos denominar «activos» de prestigio materialmente reconocibles, siendo ellos la «casa-torre / la iglesia de patronato / el molino / la ferrería y el puente», un grupo de edificaciones que funcionan holísticamente, en relación con un centro vertebrador que es la residencia señorial. Es interesante observar también, dentro de la dinámica discursiva, como aparece reflejada la oposición con los otros agentes de articulación territorial del espacio septentrional: las villas y ciudades.

Sin embargo, en este artículo, centraremos brevemente nuestra mirada sobre estas representaciones materiales del poder de los parientes mayores y como se referencian las mismas a los linajes principales.

Habíamos señalado que solar y linaje constituyen en cierta forma una unidad de sentido, su «materialización» es la erección de la «casa-torre»o «casa-fuerte». En el relato banderizo adquiere la densidad de punto genético de emergencia del linaje: 
"El linaje de Asúa fue de buenos escuderos que poblaron allí que suçedieron... E d'éstos, de los que ay más memoria fueron Garçi Sánchez d'Asúa... e Juan Sánchez de Asúa fizo la torre (casa-torre) de Asúa e su fazimientod'este linaje de Asúa fueron sus creçidas por ser mareantes en sus naos e omes onrados... e los más parientes que son en aquel linaje son de su generaçión. E tienen buenas rentas e han seido e son vasallos del Rey." (L. García de Salazar, 1492 [1999], p. 812)

"El linaje de Çugasti fueron e son buenos escuderos. E el que allí pobló primero... del que más memoria ay fue Ínigo Martínez, alcalde de Çugasti, que ovos fijos a Martín Íniguez e a Ínigo Martínez de Çugasti e el uno pobló en Çugasti e el otro en la Rabeçua, que fizo una torre (casa torre) çerca de la villa e fue alcalde.” (L. García de Salazar, 1492 [1999], p.813)

El texto de las Bienandanzas e fortunas se encuentra «plagado» de este tipo de menciones de las que solamente, y a modo de ejemplos, hemos seleccionado las evocaciones a estos dos linajes vizcaínos, los Asúa y Zugasti, ubicados primigeniamente en el valle de Erandio. Dos elementos básicos se conjugan en la propia definición de casa-torre, determinados por la funcionalidad que cumplían las mismas, por un lado, aquella representada por la dimensión doméstica por la cual es la residencia señorial en la cual vive el pariente mayor y aquel primer círculo de lealtades contraídas en torno a su familia y criados, por el otro, la dimensión militar en términos de que su construcción depende de su utilidad como fortaleza. Ambas dimensiones determinan la forma típica ${ }^{13}$ que presenta su construcción, ya que si bien estas casas-torres no eran el único lugar donde podía vivir el señor, sí representaban aquéllas donde acudía en momentos de peligro y, al mismo tiempo, eran los puestos fundamentales para controlar el territorio y las comunicaciones.

De planta cuadrada o rectangular y de dimensiones variadas, dependiendo de la longitud de las vigas maestras (troncos de hayas o robles) las gruesas paredes permitían levantar la construcción en altura - en general 3 o 4 pi sos - lo cual permitía dotar a la misma de funcionalidad defensiva, pero también se convierte en símbolo de la grandeza alcanzada por estos linajes septentrionales. La importancia simbólica de las mismas también se refleja en las acciones disciplinantes ejercidas por el propio monarca sobre los díscolos parientes mayores. Por ejemplo, en la Real Provisión del Rey Enrique IV, de 1457, después de que la villa de Mondragón (provincia de Guipúzcoa) fuera quemada por D. Beltrán de Guevara, señor de Oñate, el monarca mandó «desmochar» las casas torres de los caudillos de ambos bandos: “... algunas torres e Casas fuertes e Llanas de la dicha provincia, cuando fui a ella, les mandé allanar por que los dichos males e daños que de ellas de hacían y se cometían cesasen." (C. de Echegaray, 1991, p. 358) ${ }^{14}$

Otro ejemplo de esta situación es relatado por el propio L. García de Salazar. Narra la resolución tomada por la corona en referencia al castigo impuesto a los parientes mayores de los poderosos linajes vizcaínos de los Butrón y los Avendaño por las luchas intestinas llevadas adelante en la villa de Munguía en el año de 1414:

“... fecha tregua por el corregidor Gonzalo Moros e esparcidos las gentes, fueron emplazados a corte Gonzalo Gómez e Juan de Avendaño por la reina doña Catalina, que era tutora del rey don Juan. E llegados a corte, mandó derribar ambos los cadalsos que ellos avían fecho delante la dicha villa e tardaron allá tres años por los dichos escándalos." (L. García de Salazar, 1492 [1999], p.885)

Como vemos, más allá del valor simbólico que estos elementos tienen desde la antigüedad clásica, es claro que ellos son algunos ejemplos que nos permiten observar la importancia que adquieren en el discurso de los parientes mayores este centro referencial de la vida política y doméstica que son las casas-torres al interior de una verdadera «oikonomía» del poder.

Las «iglesias de patronato» conforman otro de los espacios arquitectónicos fundantes de la memoria. La definición del fenómeno como el de «iglesias propias ${ }^{15}$ indica precisamente la unidad de sentido que adquieren estas construcciones como santuarios de la memoria de los antepasados. El propio L. García de Salazar refiere y reivindica la importancia del patronazgo laico y la fundación de estas iglesias constituyéndolo, en gran medida, en una de las expresiones materiales y simbólicas propias de la aparición de los grandes linajes:

“... e por falta de iglesias cataron entre sí personas tenedores e diligentes que en ciertos logares edificasen iglesias e monasterios porque en ellas se cantasen misas e se rezasen las oras e se diesen los sacramentos, según la Madre Santa Iglesia, e hubiesen sus enterramientos, aunque al principio no se encerraban dentro de ellas, sino fuera, en sus sepulcros de piedra, como en muchos logares parecen hoy día...” (L. García de Salazar, 1492 [1999], p.1039). 
La cita, aunque demasiado larga para componerla completa aquí, contiene las ideas necesarias para condicionar la imagen propuesta por el cronista: 1) la desorganización primigenia se transforma en organización cuando la comunidad nombra, entre ellos, un superior, 2) siendo este el origen de las «iglesias propias» y 3) se convierte en centro religioso y lugar de la memoria del linaje. En este sentido la conclusión es lógica, "quien lograba ostentar la titularidad de la institución se apropiaba del sentido último y más trascendente de la propia existencia de la comunidad, ejerciendo su protección espiritual" (J. A. Achón Insausti, 2006, p.229). De esta manera, la erección de estas iglesias de patronato o privadas objetivan el dominio político y la preeminencia alcanzada por estos parientes mayores, son parte funcional del conjunto de estructuras materiales y simbólicas que expresan su poder. Algunos historiadores han definido este proceso como el de «domesticación del parentesco» al convertir las comunidades extensas de parientes nucleadas primigeniamente en torno a monasterios, parroquias o anteiglesias, en comunidad cristiana. ${ }^{16}$ Debemos entender que estas iglesias privadas materializan una unidad inescindible entre religión y poder señorial, es así como lo entendían los propios contemporáneos. Un buen ejemplo de ello se encuentra en la forma en que se determina la obtención del «derecho de patronato» en el texto de las Partidas de Alfonso X: “... este derecho gana home por tres cosas: la una por el suelo que da en que se faga la iglesia; la segunda por facerla; la tercera por el heredamiento que el da que llaman dote..." (Partidas, cap. 25, X de iure patronatus, III, 38)

Con la finalidad de abreviar el relato, tanto el «molino», como la «ferrería» y el «puente» configuran los otros tres elementos distintivos de esta arquitectura del poder en los territorios del septentrión castellano. Son fuentes de rentas, claro está, para los parientes mayores, pero también como hemos dicho, «signos» arquitectónicos de su poder. En las Bienandanzas e fortunas, estas construcciones tienen un lugar central, tomemos por ejemplo las menciones que realiza la crónica sobre los atributos que marcan el origen del linaje de los Artunduaga:

"El linaje de Artunduaga fundólo Juan Ferrández de Artunduaga, que fue un mercadero llano e fizo la torre e la ferrería e los molinos e el palacio de Artunduaga. E ovo una fija heredera e casóla con Sancho Ortiz de Çamudio, fijo de Sancho Ortiz, hermano de Ordoño, e heredó aquel solar con ella. E ovo fijo heredero a Sancho Ortiz de Artundoaga, que dejó fijos e fijas e fue Merino de Uribe; e dejó buenos fijos e parientes e rentas" (L. García de Salazar, 1492 [1999], p. 818)

Como vemos, L. García de Salazar señala como origen de este linaje bilbaíno una familia enriquecida de comerciantes que termina entroncándose con el poderoso linaje vizcaíno de los Zamudios, a través del matrimonio de su hija -heredera del solar principal- con Sancho Ortiz. De esta manera tenemos así, resumidos en un mismo movimiento, el origen del linaje de los Artunduaga, a través del entronque matrimonial y de aquellos elementos materiales que conforman su solar originario: torre / ferrería / molinos y palacio. Como vemos el autor pondera, en un mismo nivel de significación, la importancia que adquiere la titularidad de estos como manifestación de la preeminencia política alcanzada por este linaje en ese lugar.

En el antiguo fuero de Ayala (1373) se alude esencialmente al derecho de la erección de molino por parte de los hijosdalgo:

"...Otrosi todo home fijosdalgo pueda ganar rueda o molino en su heredad o en el egidoaforrandolo con abonadores fijosdalgo, o faciendo la presa con vidigaza e pasando el agua al solar de la rueda o molino e faciendo farina con perro, e gallo e gato" (Fuero de Ayala apud Santa María de Muniategui, A. 1984, p.378). ${ }^{17}$

En este sentido, el texto es claro en términos de que el hijodalgo puede «ganar rueda», como sinónimo de construir el molino (las piedras de moler eran el centro y sentido de toda la edificación) tanto en su tierra (su heredad) como en las tierras comunales (el ejido) aforándolo, es decir, contando con el apoyo de 3 hidalgos para constituir su titularidad. Como se puede observar los molinos que presenta este antiguo fuero no son edificaciones comunes, sino molinos hidráulicos complejos cuya construcción demandaba, más allá del lugar específico de emplazamiento (espacio bien comunicado cerca de afluentes hídricos) y de los derechos sobre la utilización agua (permisos reales o señoriales), una fuerte inversión de dinero acompañado de conocimientos técnicos adecuados. En una economía de base fundamentalmente agraria dichas edificaciones 
se constituían en un centro de interrelaciones de primordial importancia para el conjunto de la comunidad. En ese sentido el Fuero de Vizcaya (1452) condena con la «muerte» a cualquiera que “... a sabiendas, quebrantare molino" (Fuero de Vizcaya, 1452, cap. XLVIII)

Al mismo tiempo, la explotación del mineral de hierro era una actividad central para las economías señoriales del espacio septentrional. De esta manera las «ferrerías» se convirtieron en edificaciones que no solo observaban una dimensión productiva - fundamental para las rentas de los señores feudales - sino también como manifestaciones edilicias del control y explotación territorial ejercido por los parientes mayores.

Si bien la producción de hierro y la explotación férrica en estos espacios septentrionales es muy antigua, las primeras menciones documentales de la participación directa de los linajes en las mismas van desarrollándose desde fines del siglo XIII, en adelante, coincidiendo con la generalización de las ferrerías hidráulicas en el siglo XIV-XV (J. L., Orella Unzué, 2013). Los privilegios concedidos por la monarquía para el usufructo en la actividad férrica impulsaron a los parientes mayores a participar activamente en este tipo de explotaciones. En el Fuero de ferrerias (1338), concedido por el rey Alfonso XI para el espacio guipuzcoano se afirma:

\footnotetext{
"Mandamos que en los nuestros montes que son en la nuestra tierra de Guipuzcoa, por do quier que sean, en qualquier o en qualesquier lugares, salvando las heredades propias de los / fijosdalgo o de otros omes, que estan señalados de antiguamente acá, que son nuestros montes e nuestros yerrmos, que puedan cortar qualesquier árboles de qualquier manera que sean para fasercarbon e otras cosas cualesquier para las dichas ferrerías. Otrossy, mandamos que lieven el fierro e puedan levar e sacar por mar e por tierra, a do entendieren meior aprovecharse del fierro que labraren en las dichas ferrerías, pagando ellos los nuestros derechos allí do los deven pagar, segunt que sienpre lo ussaron sacar. Otrosy, mandamos que los dichos ferreros, para faser sus cassas e sus ferrerías o molinos o ruedas que non ayanenbargo ninguno, non fasiendo perjuicio a otros ningunos, según Fuero de Ferrerías" (Fuero de Ferrería. Libro 1, de Privilegios, legajo 1, n\# 7)
}

Como pariente mayor nuestro cronista banderizo en sus Bienandanzas e Fortunas también señala la importancia que adquiere el control y la expansión los derechos de titularidad sobre estas explotaciones para el acrecentamiento del linaje:

“Lope Garçía de Salazar ganó a Sant Pedro de Galdanes, aunque su padre lo ganó para él, seyendo él moço... e ganó a Sant
Llorente de Virbuxillo, que era de su patrimonio, e ganó del Rey en tierra... Galdames e de Somorrostro e la alcaldía de
Sopuerta. E ganó diez mil maravedís en los derechos de la prebostad de Portogalete, más de lo qu'el padre dexó en ella. E
compró la merindad de Castro a Ferrand González de La Marca, que la tenía en merçed del Rey, e asentóla en tierra en los
libros de Vizcaya. E fizolasferrerías e casas de Carrança e losmolinos e mançanales; edeficó e comprólas casas d'Eslares e de
Çerdigo e la torre de Vitoria e viñas d'Eslares e de Castro. E conpró la torre e azeñas de Velmonte a Ferrand González de
La Marca e conpró... la ferrería del Arenado... E conpró el solar de Juan de la Carrera e el de doña Inés de Memerea e fizo la
casa e torre e palaçios de Sant Martín e las ferrerías de los vados e molinos. E la ferrería de Urduñedigietaconpróla e fizo la
ferrería de Achuriaga e el camino de Pucheta...” (L. García de Salazar, 1492 [1999], pp.840-841)

Finalmente, debemos decir que, en lo referente a los derechos ejercidos sobre «puentes»y «portales», estos configuran la manifestación plena del control territorial ejercido por los parientes mayores. Ubicados en lugares estratégicos que interconectan los distintitos circuitos de comunicación, permitían regular directamente la imposición de rentas por su utilización. En este sentido, es claro que los abusos cometidos generaban constantes reclamos a la corona. Por ejemplo:

"Algunos vecinos de Bitoria se me enviaron a querellar y dizen que algunos del dicho lugar que andan caminos que vien de
Castiella a Navarra e a otras partes con sus mercadorias... que salen a ellos omes poderosos de la tierra e otros omes que les
toman y prenden forzadamente lo que les fallan, contra su voluntad, deziendo que les den de cada bestia e azemila, ciertos
dineros de guia que dizen que han de aver..." (Orden de Pedro I apud C., González Mínguez, 1982, p.586)

Si bien estas quejas son constantes, lo que nos permiten observar estas acciones como una práctica común, aquello que nos interesa rescatar aquí es cómo aparece en la documentación la constitución de estos dispositivos arquitectónicos, configurando territorialmente los espacios de control efectivo de estos linajes. Un ejemplo claro podemos extraerlo de la propia crónica de las Bienandanzas e Fortunas, a partir de la 
narración de los eventos producidos en el valle de Orozco en Vizcaya a principios del siglo XV. Por el control del valle en se enfrentaron dos poderosos linajes vizcaínos, los Ayalas y los Avendaño, registrándose allí tres grandes conflictos armados. El primero de ellos, que inicia el ciclo de contiendas, es la intrusión de Martín Ruiz de Abendaño reclamando sus derechos sobre la «tercera parte de las tierras de Orozco»:

\begin{abstract}
"En el año del Señor de mil CDXII años entró Martín Roiz de Avendaño en el valle de Orozco con todos sus parientes e barreóse en Archevala, que es ençima del valle de Orozco, que tenía allí algunos labradores. E eran con él los de Anuçiay e Ferrand Pérez de Ayala, fijo de Pero López, (que) era en la corte. E fizo grandes varreras e armó una casa de madera. E commo lo sopo doña María Sarmiento, muger del dicho Ferrand Pérez, llamó toda la gente de la casa de Ayala e a todas sus parentelas; e venieron en su ayuda don Pero Velas de Guebara e Sancho Sánchez de Velasco e Sancho de Leiba e Ochoa de Salazar e los Çamudianos de Salzedo e con Lope / Garçía de las Ribas e otros muchos. E toviéndoloçercadoescaramuçando cada día e mucho apretado, vino Juan Alonso de Múxica con todos los suyos parientes en ayuda d'él." (L. García de Salazar, 1492 [1999], pp. 924-925).
\end{abstract}

Es interesante rescatar del relato la mención de que "fizo grandes varreras e armó una casa de madera" pues pone de manifiesto que fortificó las entradas al territorio controlando así las comunicaciones internas del mismo, su presencia señorial. El dominio de los caminos, además de un asunto estratégico, era un negocio tan lucrativo como para encender trifulcas, contiendas de todo tipo y asesinatos.

Como podemos apreciar, en el sentido asumido por nuestro recorrido, estos conjuntos edilicios particulares: la «casa-torre» / la «iglesia de patronato» / el «molino» / la «ferrería y el puente», se nos presentan como señales materiales de la articulación territorial impuesta por estos linajes poderosos a escala local. Es decir, no son solo meros elementos «arqueológicos» de un patrimonio arquitectónico o técnico diseminado geográficamente sino más bien como rastros materiales de una compleja forma de estructuración de los espacios locales y regionales centrada necesariamente en el poder y la preeminencia política alcanzada por estos parientes mayores. Forman parte de un «topo discursivo»-alzado en piedra y madera - en conjunto tendiente a servir de clara manifestación territorial del poder alcanzado por estas grandes familias. Al mismo tiempo, cada una de estas edificaciones centraliza un agregado semindependiente de relaciones y procesos complejos que, a partir de los privilegios, otorgamientos y gracias concedidos a los parientes mayores, les permite monopolizar, potenciar y hacer efectivos sus pretendidos derechos en los espacios locales.

\title{
LA CONSTRUCCIÓN DE UN “NOSOTROS” REFERENCIAL
}

Todo discurso político funciona como dispositivo generador de inclusiones (constitutivo de un «nosotros») y de exclusiones (los «otros»). Hemos podido observar cómo estas mecánicas de diferenciación determinan la emergencia de una particular arquitectura que caracteriza la dimensión material y simbólica del poder de los parientes mayores. Fuimos apoyándonos para ello — más allá de los rastros arqueológicos y arquitectónicos - en las propias referencias utilizadas en las crónicas banderizas para entender el funcionamiento de este tipo de representaciones materiales al interior del propio relato. Queda ahora, por delante, señalar el conjunto de ideas fuerza que permiten configurar y legitimar la posición diferencial que presentan estos linajes principales actuantes en el territorio del septentrión castellano. Hablamos así de un conjunto de arquetipos configuracionales que sostienen y articulan — al interior de la trama discursiva - el propio relato de poder.

Un primer elemento, podríamos denominarlo el «mito de selección natural de los principales». El lugar que ocupan estos parientes mayores al interior de sus comunidades deviene del hecho de que los mismos son descendientes de aquellos que -en los momentos de peligro- fueron elegidos como sus «principales», «defensores del reino» al servicio del rey y por lo tanto «cimiento», «tronco», «cepa» del que proceden todos los «hidalgos de esta patria»:

"Los dichos parientes mayores como son anteriores y mejores y fundadores d'esta Provincia siempre han usado e usan y usaran de servir a sus Altezas con sus armas y caballos y escuderos y parientes en especial contra los enemigos de la santa fe 
católica así como contra moros e turcos e otros infieles por lo cual tienen el patronazgos y las décimas, así por mano de sus Altezas... en todos los tiempos de necesidad han defendido toda esta patria de todas las guerras que se han ofrecido en todas estas fronteras de Francia, de Navarra e Ynglaterra, como caballeros e hidalgos e defensores de la patria e fundadores de ella e cimiento e tronco e cepa del que proceden todos los hidalgos de esta patria."(AGG-Gipuzkoakoartxiboorokorra. JD IM $1 / 6 / 18$, fol. 8r a 9v apud Lema, J. A., 2002, p. 316)

Es más, en el sentido ontogénico dicho mito funciona en términos absolutos, es decir, la existencia misma de la comunidad, su origen y erección se encuentra configurada y firmemente enlazada al surgimiento de estos linajes principales:

"Contado a la istoria de la destruiçiónd'España cómo en el reinamiento de los Reyes de León e de Navarra e Condes de Castilla estas tierras fueron pobladas de gentes venedizas e fueron echados de sus heredamientos por los moros, segund se contiene en la dicha su persecuçión, e otrosí de gentes de otros señoríos que en ella venieron a poblar, segund dicho es en las sus poblaçiones, por los ayudar [a] defender de los dichos moros a serviçio de Dios; e vivían derramadas e no ayuntadas las pueblas, ca no poblaron villas en grandes tiempos. E por falta de iglesias cataron entre sí personas tenedores e deligentes que en çiertos logares hedificasen iglesias e monasterios..." (L. García de Salazar, 1492 [1999], p.1039)

¿Qué tenemos antes de la existencia de los parientes mayores? Nada, simplemente “... gentes venedizas e fueron echados de sus heredamientos por los moros..." Dicho agrupamiento anárquico y heteróclito se formaliza como comunidad al momento de seleccionar, entre ellos, sus principales. Amparados en el ius gentium - en tanto todo pueblo libre puede instituir por encima suyo un superior - se debe entender que dicho origen humano no excluía perse la voluntad divina, pues Dios se sirve siempre del pueblo como su instrumento. Las derivaciones racionales de tal esquema argumentativo son simples, el origen exegético de estos parientes mayores -de donde emanaba su legitimación- reside en el derecho divino y natural, ya que todo señorío es entendido también como sumisión voluntaria y contractual de la comunidad gobernada: pactum subiectionis. ${ }^{18}$

De esta manera, en este tipo de relato debe entenderse que «comunidad» / «iglesia propia» / «linaje»comportan una misma unidad de sentido originario, todos son erigidos por un mismo acto de creación voluntario y son, por ello, inescindibles. ${ }^{19}$ Por supuesto, ello conlleva también el hecho estatuido de un conjunto plural de derechos señoriales que se yerguen al momento mismo de dicha elección voluntaria por parte de la comunidad y que son trasmitidos a aquellos que conformen la descendencia legítima del linaje. En este sentido, la regulación precoz de la trasmisión de bienes acompañó la configuración de la nobleza como grupo estamental. por ejemplo, en el reino de Navarra el llamado Fuero Antiguo - la base de lo que luego será Fuero General de Navarra - se reconoce la facultad de los ricoshombres para designar heredero privilegiando al primogénito varón, pero que puede también darmásauna criatura que a otra,porqueno siempre se benefició al varónmayor (Fuero General de Navarra: Lib. 2, tít. 4, ley 1). Dicha forma también queda ratificada tempranamente por el llamado Fuero de Infanzones: “... porque los ricoshombres, caballeros e infanzones han de poder dar más a una criatura que a otra... en las disposiciones que hicieren los padres de sus bienes, que no fueren de condición de labradores, tienen libertad absoluta, dejando a sus hijos la legítima foral..." (Fuero de Infanzones: Lib. 3, tít. 13, ley 16). En el reino de Castilla la formulación jurídica evolucionará hacia el siglo XIV en la figura del «mayorazgo», definido como la: "forma de propiedad vinculada en la cual el titular dispone de la renta, pero no de la disposición de los bienes que la producen...” (B., Clavero, 1989, pp. 21-22) lo que determina en sí la posibilidad de imponer por el titular un orden sucesorio predeterminado - generalmente primando la primogenitura - pero que puede adoptar o privilegiar otras líneas de trasmisión de ser necesario.

Un segundo elemento es la «construcción del mito de la exaltación y glorificación del linaje». El sentido final que impulsan las crónicas banderizas es la revalorización de los orígenes, la deconstrucción de la memoria de estos linajes utilizando, para ello, un discurso «mítico-político» centrado en dotar de antigüedad inmemorial la fundación de las casas nobiliares y ensalzando así el solar originario del cual descienden y enlazan - de generación en generación - los distintos representantes de estos linajes mayores. Estamos en 
presencia de un relato ficcional tendiente a fijar -en forma escrita- una memoria genealógica. Debemos tener en cuenta que, al momento en que L. García de Salazar escribe sus Bienandanzas e Fortunas, muchos de estos linajes, que ya eran tomados como principales por sus convecinos, en realidad esgrimían orígenes familiares más bien modestos $\mathrm{u}$ «oscuros» sobre los cuales el cronista intenta realzar sus orígenes prosaicos, utilizando para ello un esquema mítico-ficcional. Esta operación sobre la memoria genealógica, que es un elemento central en la constitución del discurso político de los parientes mayores, permite establecer un punto genético diferencial frente al resto de la comunidad y, al mismo tiempo, legitima el lugar de preponderancia social adquirida por el linaje a través de su vinculación con sus antepasados. Debemos tener en cuenta aquí la importancia que adquiere, en este punto, la trasmisión de los valores aristocráticos a través de la «sangre». En Las Partidas, se puede observar también que su enunciación corre por estas líneas argumentativas definiendo al linaje como una «raíz»:

“... ayuntamiento de personas... como cadena, descendiendo de una rayz... La primera es una línea que sube arriba como padre o abuelo o bisabuelo... la otra que desciende: así como fijo o nieto... la otra es que viene de travieso. Esta comienza en los hermanos, e de si desciende por grado en los fijos..." (Partida IV, tít. VI, ley II) ${ }^{20}$

Al mismo tiempo, otros elementos simbólicos participan en señalar la glorificación y exaltación de la memoria del linaje, cada familia noble poseía un «apellido» y «escudos de armas» ${ }^{21}$ que los distinguía, cohesionaba y les permitía individualizarse frente a otros grupos linajísticos nobiliarios. ${ }^{22}$ Es decir, la construcción de una memoria colectiva que dotaba al individuo de un sentido de pertenencia y significación por formar parte de un linaje que, desde tiempo inmemorial, es reconocido y reputado como tal por los demás.

Finalmente, un tercer elemento es el «recurso legitimante de la violencia». La violencia banderizada no es solamente el contexto general en que se desarrolla la lucha de bandos y parcialidades de estos linajes principales en los espacios septentrionales del reino de Castilla constituye, más bien, el fundamento mismo de su existencia. Retomemos para explicarlo el propio relato banderizo:

"Dísese en las partes de la costa de Vayona e de Guípuzcoa entre los que fablan de las guerras que pasaron en ella que la primera sangre que fue vertida en ella fue entre linajes... e dízese que la causa d ello fue sobre la invidia e qualvarlía más, como fue antiguamente por todo universo mundo en todas las generaciones que en él avitaron fasta oy e seran en quanto el mundo durare..." (L. García de Salazar, 1492 [1999], p.1088)

Como vemos, lo que parece traslucir las palabras de cronista es que la violencia se inscribe en la disputa y competencia de los linajes por el «valer más», término que encubría el problema del «honor» así como también la sórdida lucha por intereses económicos y políticos que se encontraban ensamblados al interior de las estructuras parentales en cada uno de los espacios. Por ello, dicha lucha, tiene en el fondo un sentido «providencialista», forma parte de la eterna lucha entre el bien y el mal, entre Dios y el diablo, y he allí la causa primera y profunda de todas las divisiones y peleas. Motorizada por la «envidia» es intemporal: “en quanto el mundo durare". El cronista destaca que son anteriores a la propia fundación de las ciudades. Por ejemplo, hablando de la poderosa familia vizcaína de los Butrón, a la que él mismo pertenecía:

"El fijo segundo del señor de Ayangis vino a poblar Villela mucho tiempo antes de que la villa de Mungía fuese poblada, que se llamaba Juan Perez de Ayangis. E ganó eredamientos en aquellas tierras...” (L. García de Salazar, 1492 [1999], p. 1029).

Es decir, antes de que la villa fuera poblada, en estas tierras enseñoreaba «Juan Perez de Ayangis», quien ya había ganado en ella sus heredamientos. Al mismo tiempo, además, hay que tener en cuenta que el principio del honor hacía de la emulación una obligación, de manera que fundamentaba la perennidad de la ambición de «valer más». 


\section{Conclusiones:}

Como podemos observar tanto los elementos materiales como el conjunto de ideas fuerza aquí destacados forman parte de aquello que podemos definir como el discurso político de los parientes mayores norteños. Las Bienandanzas e fortunas de don Lope García de Salazar es una narrativa que permite conocer este aparato discursivo en momentos de su «cristalización». Hacia finales del siglo XV, estos parientes mayores estaban firmemente asentados en sus espacios locales de poder, catados por el resto de la población como los principales en cada uno de los lugares donde ejercían su poder señorial. Las crónicas son significan un intento de establecer sobre cada una de estas familias poderosas una memoria mítico-genealógica que permita legitimar su situación diferencial frente al resto de sus convecinos a través de un relato que «desafíe el propio tiempo», recurriendo para ello a recursos míticos y fantásticos. Sin embargo, los mismos se encuentran fuertemente correlacionados a los rasgos materiales del poder - un discurso pétreo - que define espacialmente la presencia de estos parientes mayores. Como podemos apreciar, todo el conjunto, tanto en lo simbólico cuanto, en lo material, conforman un sentido de unidad al que podemos definir como un discurso tendiente a marcar una alteridad, delos parientes mayores en el septentrión castellano.

\section{REFERENCIAS}

Achón Insausti, J. A. (2006). "Los Parientes Mayores”, en IuraVasconiae, 3, 221-247. Recuperado de: https://www.re vistaiuravasconiae.eus/es/content/3-iura-vasconiae-221-247-los-parientes-mayores

Arocena Echeverría, I. (1978). "Los parientes mayores y la guerra de bandos en País Vasco". En Historia del Pueblo Vasco I, pp. 151-172. San Sebastián: Erein

Azcárate, A. y Lasagabaster, J. I. (2004a). "La arqueología y la recuperación de las arquitecturas olvidadas". En $I V$ Congreso Internacional: Restaurar la Memoria, pp. 137-160. Valladolid: Junta de Castilla y León, Consejería de cultura y turismo.

Azcárate, A. y García Gómez, I. (2004b.) "Las casas-torres bajomedievales. Análisis sistémico de un proceso de reestructuración espacial /territorial”, en Arqueología y Arquitectura, 3, 7-37. Recuperado de: http://arqarqt.re vistas.csic.es/index.php/arqarqt/article/view/59/56

Clavero, B. (1989). Mayorazgo. Propiedad feudal en Castilla 1369-1836. Madrid: Siglo XXI.

Dacosta Martínez, A. (1999a) "De donde se sucedieron unos en otros". La historia y el parentesco vistos por los linajes vizcaínos bajomedievales", en Vasconia. Cuadernos de historia-Geografia, 28,57-70. Recuperado de: http://www.eusko-ikaskuntza.eus/es/publicaciones/de-donde-sucedieron-unos-en-otros-la-historia-y-el-pa rentesco-vistos-por-los-linajes-vizcainos-bajomedievales/art-14129/

Dacosta Martínez, A. (1999b) "Patronos y linajes en el Señorío de Bizkaia. Materiales para una cartografía del poder en la baja Edad Media”, en Vasconia: Cuadernos de historia-Geografía, 29, 21-46. Recuperado de: http://www.eusko-ikaskuntza.eus/es/publicaciones/patronos-y-linajes-en-el-senorio-de-bizkaia-materialespara-una-cartografia-del-poder-en-la-baja-edad-media/art-16844/

Dacosta Martínez, (2003) Los linajes en Bizkaia en la Baja Edad Media: poder, parentesco y conflicto. Bilbao: Editorial de la Universidad de País Vasco.

Da Graca, L. (1996). “Tributos, señores y situación campesina en behetrías y consejos de realengo. Siglos XII al XV”, en Studiahistórica, Historiamedieval, 14, 159-180. Recuperado de: https://revistas.usal.es/index.php/ Studia_H_Historia_Medieval/article/view/4470/4486

Díaz de Durana, J. R. (1998a). "Patronatos, patronos, clérigos y parroquianos. Los derechos de patronazgo sobre monasterios e iglesias como fuente de renta e instrumentos de control y dominación de los Parientes Mayores guipuzcoanos (siglos XIV a XVI)", en Hispania Sacra, 50(102),467-508. Recuperado de: http://hispaniasacra. revistas.csic.es/index.php/hispaniasacra/article/view/617 
Díaz de Durana, J. R. (1998b). La lucha de bandos en País Vasco. Guipúzcoa: de los Parientes Mayores a la Provincia (siglos XIV al XVI). Bilbao: Servicio Editorial de la Universidad de País Vasco

Díaz de Durana, J. R. (2004a). La otra nobleza. Escuderos e hidalgos sin nombre y sin historia. Hidalgos e hidalguía universal en el País Vasco al final de la Edad Media (1250-1525). Bilbao: Servicio Editorial de la Universidad del País Vasco.

Díaz de Durana, J. R. (2004b). "Las Luchas de Bandos: Ligas nobiliarias y enfrentamientos banderizos en el nordeste de la Corona de Castilla”. En J. I. de la Iglesia Duarte (coord.), Conflictos sociales, políticos e intelectuales en la España de los siglos XIV y XV: XIV Semana de Estudios Medievales, Nájera, del 4 al 8 de agosto de 2003, pp. 81-112. Nájera: Instituto de Estudios Riojanos.

Díez Herrera, C. (1990). La formación de la sociedad feudal en Cantabria (siglos XI-XIV). Santander: Servicio de publicaciones Universidad de Cantabria.

Echegaray, C. de (1991). "Por Guipúzcoa. Impresiones y recuerdos", en Revista Vascongada, Tomo XXV,406, octubre, $169-488$.

García, D. H. (1995). La nobleza en la España Moderna. Madrid: Istmo.

García de Salazar, L. (1492 [1999]) Edición de las Bienandanzas y Fortunas de García de Salazar. Edición realizada por Marín Sánchez, A. M. Memorabilia: boletín de literatura Sapiencial, 3, versión electrónica http://parnaseo.uv.es/ Lemir/Textos/ bienandanzas

García Gómez, I. (2003). "Claves para el conocimiento de la configuración espacial de una torre banderiza: la Torre de Murga (siglos XIV-XV), en Arqueología y Arquitectura, 2, 131-138. Recuperado de: http://arqarqt.revistas. csic.es/index.php/arqarqt/article/view/38

Gerbet, M. del C. (1989). La nobleza en la Corona de Castilla. Sus estructuras sociales en Extremadura (1454-1516). Cáceres: Institución Cultural "El Brocense" de la Excma. Diputación provincial de Cáceres.

Gierke, Otto Von (1995). Teorías politicas de la Edad Media. Madrid: Centro de Estudios Constitucionales.

González Cembellín, J. M. (2004.) Torres de las Encartaciones, 2 vols. Bilbao: Diputación Foral de Bizkaia

González Mínguez, C. (1982). "Algunos aspectos del abastecimiento de Vitoria en la Edad Media”. En Actas del Congreso de Estudios Históricos. Vitoria en la Edad Media, pp. 565-602. Vitoria: Vitoria-Gasteiz

Lema Pueyo, J. A.; Fernández de Larrea, J.; García, E; Larragaña, M.; Munita, J. A. y Díaz de Durana, J. R. (2000). Los señores de la guerra y de la tierra: nuevos textos para el estudio de los Parientes Mayores guipuzcoanos (1265-1548). San Sebastián: Diputación Foral de Gipuzkoa.

Lema Pueyo, J. A.; Fernández de Larrea, J. A.; García, E.; Larragaña, M.; Munita, J. A. y Díaz de Durana, J. R. (2002). El triunfo de las elites urbanas Guipuzcoanas: nuevos textos para el estudio del gobierno de las villas y de la Provincia (1412-1539). San Sebastián: Diputación Foral de Guipúzcoa.

López Benito, C. I. (1983). Bandos nobiliarios en Salamanca. Salamanca: Centro de Estudios Salmantinos

Mantecón Movellán, T. A. (1997). Conflictividad y disciplinamiento social en la Cantabria del Antiguo Régimen. Santander: Universidad de Cantabria - Fundación Marcelino Botín.

Marín Paredes, J. A. (1998). "Semejante pariente mayor": Parentesco, solar, comunidad y linaje en la institución de un Pariente Mayor en Gipuzkoa: Los señores del solar de Oñaz y Loyola (Siglos XIV-XVI). San Sebastián: Departamento de Cultura y euskera, Diputación Foral de Gipuzkoa, Ikerlanak/Estudios.

Martínez Sopena, P. (Dir.) (1995) Sistemas de identificación hispano-cristianos en los siglos IX a XIII. Valladolid: U. de Valladolid - U. de Santiago de Compostela.

Menéndez Pidal de Navascués, F. (1993). Los emblemas heráldicos. Una interpretación histórica. Madrid: Real Academia de la Historia.

Orella Unzué, J. L. (2013) “Territorio y sociedad en Guipuzkoa Medieval: Los Parientes Mayores", Lurralde, Investigaciones Espaciales, 36, 67-119. Recuperado de: https://dialnet.unirioja.es/servlet/articulo?codigo=5520 082

Santa María de Muniategui, A. (1984). "Los molinos hidráulicos en el Fuero de Vizcaya”. En Congreso de Estudios Históricos, Vizcaya en la Edad Media, pp.375-382.San Sebastián: Sociedadde estudios vascos - EuskoIkaskuntza. 
Solórzano Telechea, J. A. (2004). “Sociedad y violencia de bandos en la Merindad de Trasmiera durante la Baja Edad Media”. En Estudios Trasmeranos vol. 2, pp. 178-201. Cantabria: Exmo. Ayuntamiento de Noja.

Ybarra y Berge, J. (1958). Catálogo de monumentos de Vizcaya, 2 tomos. Bilbao: Imprenta provincial de Vizcaya

\section{Notas}

1 La sociedad castellana septentrional bajo medieval se nos presenta compleja y variada. Tanto en los valles y aldeas que conforman su paisaje rural como así también en las numerosas villas del interior y de la costa que configuran su tímido e incipiente sistema urbano la imagen es colorida y plural. Bajo la condición jurídico social de «hidalgos norteños» tenemos un amplio abanico de tipos sociales que van desde los «labradores» (término genérico que designa en la documentación al campesino parcelario sometido a censo) a los mercaderes exportadores (sectores enriquecidos por el monopolio en la explotación del hierro y el comercio marítimo) hasta aquellos, que por su poder y ascendencia son considerados parientes mayores.

2 Para profundizar en la forma en que se estructuran las relaciones en torno al cabeza de linaje, véase el trabajo anteriormente citado de J. A. Marín Paredes (1998).

3 Véase J. R. Díaz de Durana (2004a).

4 Sobre el problema de la conflictividad en estos espacios, existeuna amplia bibliografía, cabeconsignar aquí algunos textos fundamentales sobre el tema: I. Arocena Echeverría (1978); T. A. Mantecón Movellán (1997); J. R. Díaz de Durana (2004b) entre muchos otros.

5 Como establece C. I. López Benito (1983) los linajes deben ser entendidos como: “... una comunidad de individuos unidos por lazos de sangre y por un intenso sentido de la solidaridad. Entre sus componentes destacaba siempre un jefe o pariente mayor que tenía... importantes atribuciones (repartir cargos, poner en pie de guerra al linaje) Pertenecen también a éste las clientelas constituidas por personas vinculadas a él por lazos de tipo espiritual (fidelidad, vasallaje, etc.) La solidaridad era básica para la supervivencia del linaje." (p. 58)

6 El solar originario (materialidad del vínculo adscriptivo) consolidaba todos los elementos materiales y simbólicos que contribuían a la grandeza del linaje: la «casa-torre», el «hogar», el «molino», la «ferrería» y la «iglesia», pero también era el “... solar antiguo e poderoso e su fundamento... de dónde sucedieron e suceden de unos en otros..." (L. García de Salazar, 1492 [1999], p.809), es decir, lugar mítico donde se constituye una conciencia de un origen - si empre remoto - de un antepasado común a todos los miembros del linaje y donde las leyendas sirven para mistificar sus principios.

7 De esta manera, la memoria genealógica se convierte en un vínculo inmaterial que determina la conexión entre los miembros adscritos al linaje. Configuran una matriz común que los enlaza a un pasado común -mítico y glorioso- del cual descienden, “unos en otros...” (L. García de Salazar, 1492 [1999], p.809)

8 Como establece M. del C. Gerbet (1989) “... era raro que todos los miembros de linaje fuesen sepultados en el mismo sitio. Esto se debía, por una parte, a la evolución del sentimiento religioso... por otra parte, las tumbas familiares edificadas en las iglesias comenzaron a ser insuficientes. El pariente mayor entonces, a veces, se encargaba de acordar o no la autorización para enterrar a tal o cual miembro del linaje en el enterramiento familiar. Algunas familias, sin embargo, reservaban el entierro principal del linaje sólo para los primogénitos." (p. 98)

9 Véanse los análisis realizados por J. R. Díaz de Durana (1998a); A. Dacosta Martínez (1999b). Tanto A. Dacosta Martínez como Díaz de Durana, focalizan su atención en el estudio del valor que supusieron las rentas originadas en estas iglesias y en la influencia social que se derivó de la detentación de prerrogativas sobre estos oratorios.

10 Para algunos historiadores el escudo de armas es el elemento central de la autoconciencia nobiliar, aún más que el apellido. Sin embargo, ambos también se encuentran inextricablemente unidos. Para el lugar que ocupan estos emblemas véase F. Menéndez Pidal de Navascués (1993). Según D. H. García (1995) “...en las armas venía de algún modo señalada la 'calidad' de la familia noble, por sus alusiones, muchas veces leyendas, sobre cómo se consiguieron...de ahí que se colocaran en las partes más visibles y se conserven hoy en las fachadas de las antiguas casas nobles." (p. 43)

11 "En el tiempo que reinaba el rey don Rodrigo... murió un gran caballero de los godos... y dejó a su fin dos fijos, uno legítimo y otro bastardo, que acá dicen de ganancia. E el legítimo, que heredó la casa, salió omne débil y simple... y amenguó mucho en el estado de la casa que su padre... el otro hijo que dejó de ganancia salió... esforzado caballero e ganó con guerras e trabajos sirviendo al rey don Rodrigo... contra los moros... el hermano legítimo dijo ante el Rey: - Señor, bien sabe la vuestra merced que ningún hijo de ganancia no puede traer las armas derechas de su padre, habiendo fijo legítimo, en ninguna parte del mundo. Pido por merced que mandes a mi hermano, que aquí está, que quite las armas que mi padre me dejó de su bandera, pues es fijo de ganancia... El hermano menor, que bien oyó la demanda que le avía hecho, dijo al Rey: -Señor, a lo que mi hermano dice que yo le deje las armas que mi padre le dejó, pues yo soy de ganancia, señor, por cierto, él dice la verdad, que yo soy de ganancia; e digo que él es de pérdida, pues él perdió y amenguó la honra 
y casa que su padre y mío le dejó. E pues yo gané en ella lo que él amenguó, más razón es que yo haya las sus armas, siendo ganador, que él, siendo perdidoso. Pido merced que las otorgues para mí y para todos los bastardos de España que son o serán en ella. E si no me lo otorga, de aquí me iré tornar moro en vuestro deservicio.” (L. García de Salazar, 1492 [1999], p. 544).

12 Véase cuadro 1: Frecuencia de locativos. En negrita número absoluto de repitencias en el texto de las Bienandanzas e Fortunas. Soporte programa QDA Miner de análisis lexicográfico.

13 Se establecen en general fenotipos generales en la zona septentrional debido a los materiales predominantes en ellas: casatorre de madera y el de casa-torre de piedra. Trabajos arqueológicos y de la historia de arquitectura son especialmente útiles para el análisis de estas construcciones. Especialmente señalaremos aquí los siguientes: J. Ybarra y Berge (1958); I. García Gómez (2003); J. M. González Cembellín (2004); A. Azcárate y J. I. Lasagabaster (2004a) y A. Azcárate y I. García Gómez(2004b). Entre otros muchos trabajos sobre el tema.

14 Véase dicha referencia en C. de Echegaray (1991). Las acciones disciplinantes, en general pasaban justamente por el «desmochamiento» o «derribo» de estas casas-torres y por el destierro, evitando así dar muerte a aquel que, por renovados servicios, puedan recuperar su posición por perdón real.

15 Véase para este problema A. Dacosta Martínez (1999b).

16 Véase J. A. Lema Pueyo et al (2000).

17 Citado en el trabajo de Sáenz de Santa María de Muniategui, A. (1984, pp.375-382) "Los molinos hidráulicos en el Fuero de Vizcaya”, Bilbao, Congreso de Estudios Históricos, Vizcaya en la Edad Media, 1984, pp. 375-382.

18 Todo poder emana de la libre como "subiectio inferiorum" y surge "per viam voluntariae subiectionis et concensus" (por medio de la sumisión voluntaria al consenso), según lo expone el propio Nicolás de Cusa. Citado por Gierke, Otto Von (1995, p. 154).

19 Como afirma el propio Otto Von Gierke (1995). La teoría política medieval "no considera en modo alguno como principio propiamente constitutivo del grupo el proceso natural de crecimiento, sino que recurre siempre a la idea de creación. Por consiguiente, de una parte, un acto divino de creación aparece como fuente última de la existencia de toda agrupación social...” (p. 132)

20 Más adelante, en el siglo XVI, Covarrubias llama «linge»: decendencia de las casas y familia. Es decir, «línea»: porque van descendiendo de padres, hijos y nietos, etc., como una línea recta. Parentela: los parientes de un linaje. En cuanto «parie», el deudo que es de un mesmo linaje, «latine cognatus». Dígase de «parens», «tis», padre o madre, de los dos y de ahí: parentela.

21 Para el lugar que ocupa estos emblemas véase F. Menéndez Pidal de Navascués (1993).

22 Véase P. Martínez Sopena (1995). 